\title{
ОСНОВНЫЕ НАПРАВЛЕНИЯ ИССЛЕДОВАНИЙ ДЕЯТЕЛЬНОСТИ СОТРУДНИКОВ ГПС МЧС РОССИИ
}

\section{THE MAIN DIRECTIONS OF RESEARCH ON THE ACTIVITIES OF EMPLOYEES OF THE MINISTRY \\ OF EMERGENCY SITUATIONS OF RUSSIA \\ O. Orlova}

Summary: The analysis of the main directions of research of the activities of employees of the State Fire Service of the Ministry of Emergency Situations of Russia. The effective means of socialization influencing the efficiency of decision-making by the head in extreme situations are revealed. The genesis of the ideas of socialization of the scientific and theoretical foundations of professional training of the heads of departments of the State Fire Service of the EMERCOM of Russia is shown. The author notes that at the present stage of development in the EMERCOM of Russia the role of management personnel has significantly increased, which predetermined the need to improve the system of their training. Against this background, the article examines the main methods and technologies of such training, focuses on the factors that should be taken into account in the educational process. The article also notes that the activities of the EMERCOM of Russia employees will be effective only if the EMERCOM employees themselves, as well as their leaders, are aware of the need to constantly improve the methods of carrying out their activities and choose the most optimal ways for this. As a result of the study, the author of the article points out that the formation of an EMERCOM specialist should include the formation and development of systems thinking, analysis, synthesis. The significance of these skills is indicated.

Keywords: genesis of ideas of socialization of scientific and theoretical foundations of professional training of managers, reliability of statistical materials used and monitoring results, structural and substantive characteristics of professional training.

\section{Введение}

$\Pi$ редставляется вполне естественным, что определение потребности в тех или иных специалистах выступает в качестве самостоятельной и достаточно сложной научно-практической проблемы, решение которой осуществляется на основании различных методов, оптимальных для того или иного ведомства.

На современном этапе развития органы управления подразделениями Государственной противопожарной службы (ГПС) МЧС России испытывают острую нужду в управленческих кадрах, для которых присущ новый стиль мышления и которые обладают такими навыками,

\author{
Орлова Ольга Николаевна \\ K.n.н., дочент, Академия государственной \\ противопожарной службы МЧС России \\ olga_on.omsk@mail.ru
}

Аннотация: Проведен анализ основных направлений исследований деятельности сотрудников ГПС МЧС России. Выявлены эффективные средства социализации влияющие на эффективность принятия решений руководителем в экстремальных ситуациях Показан генезис идей социализации научно-теоретических основ профессиональной подготовки руководителей подразделений Государственной противопожарной службы МЧС России. Автор отмечает, что на современном этапе развития в системе МЧС России роль управленческих кадров существенно возросла, что предопределило необходимость в совершенствовании системы их подготовки. На этом фоне в статье рассматриваются основные методы и технологии такой подготовки, акцентируется внимание на факторах, которые стоит учитывать в образовательном процессе. Также в статье отмечено, что деятельность сотрудников МЧС России будет эффективной только в том случае, если сами сотрудники МЧС, равно как и их руководители будут осознавать необходимость постоянного совершенствования методов осуществления своей деятельности и выбирать для этого наиболее оптимальные пути. В результате проведенного исследования автор статьи указывает, что становление специалиста МЧС должно включать в себя формирование и развитие системного мышления, анализа, синтеза. Указывается значимость данных умений.

Ключевые слова: генезис идей социализации научно-теоретических основ профессиональной подготовки руководителей, достоверностью используемых статистических материалов и результатов мониторинга, структурно-содержательная характеристика профессиональной подготовки.

знаниями и умениями в области пожарной безопасности, которые необходимы для разработки стратегии развития новых территорий и социально управленческих технологий. Кроме того, нужны такие кадры, которые в полной мере понимают систему государственного и муниципального управления, оперативную и спасательную работу, хорошо разбираются в вопросах надзора и контроля.

Полагаем, что указанные тенденции предопределяют необходимость в планомерном совершенствовании системы управления профессиональным обучением, а также повышении квалификации и переподготовки руководящих кадров в МЧС России. 


\section{^итературный обзор}

В ситуации, которая сегодня сложилась в рамках системы подготовки руководителей подразделений ГПС МЧС РФ можно выделить противоречия [1-12]:

1. Первый пласт противоречий возникаем между увеличением вида работ, которые выполняются подразделениями ГПС МЧС России существующей ныне системой профессиональной подготовки руководящих должностей.

2. Определенные противоречия наблюдаются между необходимостью в том, чтобы повышать качество обучения руководителей, их мобильность и тем, что сегодня соответствующие технологии подготовки надлежащим образом так и не разработаны.

3. Кроме того, противоречия наблюдаются между необходимостью в том, чтобы совершенствовать процесс подготовки руководителей и недостатком квалифицированных специалистов, которые могут осуществлять деятельность в заданном направлении.

На современном этапе развития направлениями исследований деятельности сотрудников ГПС МЧС России являются:

- психолого-педагогическое направление (70\%), которое включает в себя психологическое направление в сфере психологического сопровождения и иное.

- организационные направления (10\%).

- материально-техническое направление (10\%), в частности, разработка различных средств, тренажеров, финансово-экономические вопросы;

- отдельные вопросы специальной подготовки (5\%) и иное (5\%).

\section{Материалы и методы}

Исследования, посвященные совершенствованию профессиональной подготовки руководителей МЧС России, оценка социальных заказов общества, а также запросов руководства МЧС России в кадрах управленческого звена. В рамках изучения данных материалов было установлено, что развитие системы дополнительного профессионального образования сотрудников МЧС является фактором, направленным на совершенствование деятельности специалистов единой системы ликвидации и предупреждения чрезвычайных ситуаций.

Сегодня необходимо обосновать и в полной мере описать ключевые стратегии по подготовке квалифицированных управленческих кадров в рамках взаимодействия образовательных учреждений, а также структурных отделений и региональных учреждения МЧС России согласно современным требованиям, которые сегодня предъявляются к обеспечению безопасности.

Также сегодня очень важно акцентировать внимание на важности вопросов, которые непосредственно связаны с системой дополнительного профессионального образования, так как данный вопрос по праву можно рассматривать как педагогический феномен, создающий условия для обучения, развития и образования, а также для развития навыков в сфере управленческих действий сотрудников МЧС. Обусловлено это тем, что навыки и знания в этой сфере способны обеспечить эффективное решение задач при ликвидации ЧС.

Отобрать, а впоследствии адаптировать системы по совершенствованию навыков сотрудников, которые относятся к руководству МСЧ России, в сфере обучения и воспитания подчиненных, управлению ими, а также изучить практику использования в управленческой деятельности последних достижений техники и науки, равно как и передовых методов и форм работы, современных технологий подготовки сотрудников.

В полной мере изучить и описать формирование и дальнейшее развитие профессиональной компетентности и организационно-управленческих компетенций сотрудников МЧС РФ, описать их стремления к планомерному совершенствованию профессиональных навыков с учетом всех особенностей управленческой деятельности.

Выработать постоянное совершенствование у личного состава практических умений и навыков управления процессами предупреждения и ликвидации ЧС.

Выполнить анализ формирования высокой устойчивости личности сотрудников, развитие у них организаторских и управленческих способностей и умений, других профессионально важных качеств для управления в кризисных ситуациях.

Полагаем, что использовать широкую совокупность решений, среди которых можно выделить такие решения, как:

- педагогические решения (в том числе, методические), различные виды;

- организационные решения, кадровые и материально-технические;

- научно-методические и медико-физиологические решения.

Также стоит описать основные решения, которые принимаются сотрудником ГПС МЧС России, а именно:

- логичные,

- нелогичные,

- интуитивные,

- частичные, 
- дифференцированные,

- интегральные

- нормативно-правовые.

В этом аспекте особой значимостью будет обладать выявление наиболее эффективных средств социализации, среди которых можно выделить совокупность таких средств. В частности, это влияние экстремальной ситуации на когнитивную сферу деятельности, а также управленческую компетентность рассмотренный как фактор, который оказывает непосредственное влияние на принятие решений. Кроме того, стоит отметить такие средства, как ресурсно-временной аспект управленческой компетентности руководителя в экстремальных условиях, социально-психологический аспект управленческой компетентности руководителя, прогнозирование эффективности принятия решений руководителем в экстремальных ситуациях.

Раскрыть генезис идей социализации научно-теоретические основы профессиональной подготовки руководителей подразделений Государственной противопожарной службы МЧС России классификация, где выделены уровни управленческой иерархии руководителей, специфика деятельности руководителей ГПС МЧС России;

Предпосылки, принимаемых сотрудником МЧС решений:

а) уровень комплексных знаний в:

- нормативно-правовых аспектах профессиональной деятельности;

- теории и методике педагогики и управления,

- медико-физиологических вопросах;

- биомеханике;

- психолого- педагогических вопросах;

- метрологии, статистике.

б) личный опыт;

в) способность принимать решения (брать на себя ответственность);

г) умения слушать, видеть, анализировать, убеждать, донести суть вопроса.

Основные направления исследований деятельности сотрудников МЧС:

- концептуальные;

- стратегическо-оперативное;

- кадровое (подготовка руководящего состава различного уровня);

- информационное сопровождение;

- информационно-аналитическое;

- адаптация - дезаптация;

- вариативное;

- эргономическое;

- региональное;

- конфликтологическое.
Для основных направлений исследований деятельности сотрудников МЧС необходимо выделить следующие этапы:

- проведение анализа структурно-содержательной характеристики подготовки руководства структурных подразделений ГПС МЧС России;

- определение путей для планомерного совершенствования данной подготовки (применительно к руководству подразделений ГПС МЧС России);

- разработка УМК в рамках педагогической модели профессиональной подготовки в рамках раздела «государственное и муниципальное управление». Данный сегмент должен содержать профессиональные блоки, методы и приемы;

- разработка специализированных алгоритмов для отбора и коррекции профессиональной подготовки руководителей подразделений ГПС МЧС России.

\section{Результаты}

Указанные этапы будут сопровождаться:

- обоснованностью методов исследования с методологической точки зрения;

- логическим построением и системностью построения теоретических и методологических оснований деятельности вне зависимости от ее этапа;

- комплексным подходом к исследованию основных проблемных аспектов;

- использование методов, которые органично дополняют друг друга и в целом адекватны поставленным задачам;

- разнообразием источников по основным ключевым областям исследования;

- репрезентативностью объема выборок; сопоставлением полученных данных с результатами, опубликованными ранее в научной литературе;

- сравнению результатов исследования; достоверностью используемых статистических материалов и результатов мониторинга;

- сочетанием качественного и количественного анализа полученных данных; - статистической достоверностью данных педагогического эксперимента;

— научно обоснованным выбором методов исследования;

- анализом и обобщением предшествующих разработок в рассматриваемой области;

- согласованностью полученных результатов с логикой особенностей и динамикой изменения различных процессов, происходящих в период процесса обучения;

- репрезентативностью выборки при проведении эксперимента;

- апробацией и устойчивой повторяемостью полученных результатов. 


\section{Зак^ючение}

В результате проведенного исследования можно констатировать, что анализ педагогических исследований, равно как и практика системы отечественного образования явно свидетельствуют о наличии интереса к проблеме формирования профессионального сознания в рамках процесса становления специалиста МЧС. Установлено, что становление специалиста МЧС должно включать в себя формирование и развитие системного мышления, равно как и умений видеть объекты в единстве многосторонних отношений и связей. Также было установлено, что на современном этапе развития существенно возрастает значимость результатов интегрированного познания, а также идей и методологических принципов системного анализа. В связи с этим, объективной необходимостью является разработка новых подходов к организации, а также к осуществлению педагогического процесса, в рамках которого основной задачей будет являться формирование знаний и приемов теоретического мышления, а также приемов по рациональному использованию знаний в целях решения профессиональных задач.

\section{ЛИТЕРАТУРА}

1. Орлова 0.Н. Диссертация на соискание ученой степени кандидата педагогических наук. Педагогическая модель профессиональной подготовки руководителей подразделений государственной противопожарной службы МЧС России 13.00.08 - теория и методика профессионального образования МЧС России. Академия ГПС МЧС России. 11.11.2010г. стр.212 (стр. 88-89,130)

2. Орлова 0.Н. Основные факторы обеспечения качества образования в пожарно-технических вузах России. Академия ГПС мЧС России. Научный журнал ISSN 2071-7342 http://ipb.mos.ru/ttb. Технологии техносферной безопасности. Выпуск 5 (63) 2015г.

3. Орлова 0.Н. Совершенствование подготовки и деятельности специалистов Единой системы предупреждения и ликвидации чрезвычайных ситуаций Афганистан болит в наших сердцах И.И. Шуманский (СПб ИПКР ФСИН РФ) 2015 (72). Издание ФГБУ «Российской академии ракетных и артиллерийских наук») - Москва 2015 Актуальные проблемы защиты и безопасности: Труды Всероссийской научно-практической конференции РАРАН (1-4 апреля 2015 г.) C. 322-325.

4. Орлова 0.Н. Профессиональная подготовка руководителей для деятельности в экстремальных ситуациях. European Social Science Journal (Европейский журнал социальных наук). 2016. № 2. Стр. 526 (стр. 364-373).

5. Орлова 0.Н., «Модернизация работы с кадровым резервом выдвиженцев на руководящую должность ФПС МЧС России на основе ряда закономерностей участвующих в управлении карьерой» Монография [Текст]/ Орлова 0.Н.//- М.:Академия ГПС МЧС России, 2017. - 157 с.

6. Орлова 0.Н., «Разработка алгоритма по совершенствованию работы в области управления профессиональным воспитанием личного состава ФПС на основе статистических данных»: Монография / Утверждено Редакционно-издательским советом Академии ГПС МЧС России.- М.: Академия ГПС МЧС России, 2017. - 128c.

7. Орлова 0.Н., «Перспективы применения социологических исследований в области обеспечения пожарной безопасности »: Монография / Утверждено Редакционно-издательским советом Академии ГПС МЧС России.- М.: Академия ГПС МЧС России, 2017. - 114с.

8. Орлова 0.Н., Развитие системы дополнительного образования МЧС России»: Монография / Утверждено Редакционно-издательским советом Академии ГПС МЧС России.- М.: Академия ГПС МЧС России, 2017. - 152с.

9. Орлова 0.Н., Совершенствование научных подходов подготовки специалистов в области государственного и муниципального управления». Монография / Утверждено Редакционно-издательским советом Академии ГПС МЧС России.- М.: Академия ГПС МЧС России, 2017. - 158с.

10. Орлова 0.Н., Монография. Социологические исследования в области обеспечения пожарной безопасности: Монография. О.Н. Орлова - М.: Академия ГПС МЧС России, 2017. -113 с

11. Орлова 0.Н., НИР по теме: «Совершенствование научных подходов в обучении с использованием индивидуализации подготовки каждого управленца В соответствии с требованиями образовательных стандартов для каждого направления специальности» [Текст]/ Орлова 0.Н.//- М.: Академия ГПС МЧС России, 2017. -158 c.

12. O.N. Orlova Scopus Improving the system of additional professional education of EMERCOM of Russia as factor of improvement of training and operations professionals unified system of prevention and liquidation of emergency situations (cтp.1454- 1460) European Sociological Review Issue 6 (2), December 2017 VOLUME 33 0xford niversity Press 2017

(с) Орлова Ольга Николаевна (olga_on.omsk@mail.ru). 